\title{
Lixiviação de potássio proveniente do termopotássio ${ }^{1}$
}

\author{
Ivaniele Nahas Duarte 2 , Hamilton Seron Pereira², Gaspar Henrique Korndörfer²
}

\begin{abstract}
Potassium leaching from thermopotash

Potassium losses by percolation or leaching can be reduced by using less soluble sources. This study aimed at evaluating leaching losses of potassium from granulated potassium chloride $(\mathrm{KCl})$, granulated thermopotash and powdered thermopotash. The experimental design was completely randomized, with three replications, in a factorial scheme with four sources (control, granulated $\mathrm{KCl}$, granulated thermopotash and powdered thermopotash) and two soil types (Ustoxic Quartzipsamment and Oxysol Red). The soil samples were added to lysimeters and moistened up to their field capacity. The potassium fertilizers were applied at $3,000 \mathrm{~kg} \mathrm{ha}^{-1}$ of $\mathrm{K}_{2} \mathrm{O}$, in the upper layer of the lysimeter, and incorporated to the first column ring $(0,05 \mathrm{~m})$, in all treatments. These columns were irrigated for 18 days, with water equivalent to a $344 \mathrm{~mm}$ rainfall. The soil solution was collected every two days and stored in $50 \mathrm{~L}$ containers. Potassium contents were determined in the leachate and in the soil, up to the depth of $0.8 \mathrm{~m}$, at the end of the experiment. The potassium leaching was higher when $\mathrm{KCl}$ was the source used. The powdered termopotash supplied more potassium to the top soil layer $(0-20 \mathrm{~cm})$, while the $\mathrm{KCl}$ supplied more potassium to the subsurface layers, presenting a higher mobility in the soil profile, regardless of soil type. The granulated thermopotash released less potash to the top soil layer than the powdered thermopotash, while no significant differences were observed for the other layers.
\end{abstract}

KEY-WORDS: Fertilization; percolation; lysimeters.

\section{INTRODUÇÃO}

O potássio, quando presente na solução do solo, movimenta-se verticalmente, principalmente pela água de drenagem. Em função deste movimento, este elemento pode ser perdido por lixiviação, ou seja, transportado para profundidades além daquelas ocupadas pelas raízes (Oliveira \& Villas Boas 2008). Esta movimentação do potássio no perfil do solo depende, principalmente, do tipo de solo, textura (Neves

\section{RESUMO}

As perdas de potássio no solo, por percolação ou lixiviação, podem ser reduzidas com o emprego de fontes menos solúveis. Objetivou-se avaliar as perdas por lixiviação do potássio proveniente do cloreto de potássio $(\mathrm{KCl})$ granulado e do termopotássio farelado fino e termopotássio granulado. $\mathrm{O}$ delineamento utilizado foi inteiramente casualizado, com três repetições, em esquema fatorial com quatro fontes (testemunha, $\mathrm{KCl}$ granulado, termopotássio farelado fino e termopotássio granulado) e dois tipos de solo (Neossolo e Latossolo). As amostras de solo foram adicionadas a lisímetros e irrigadas até sua capacidade de campo. Os fertilizantes potássicos foram aplicados à dose de $3.000 \mathrm{~kg} \mathrm{ha}^{-1}$ de $\mathrm{K}_{2} \mathrm{O}$, na parte superior dos lisímetros, e incorporados ao primeiro anel da coluna $(0,05 \mathrm{~m})$, em todos os tratamentos. Estas colunas foram irrigadas por 18 dias, com quantidade de água equivalente a uma chuva de $344 \mathrm{~mm}$. A solução do solo era recolhida a cada dois dias e armazenada em galões de $50 \mathrm{~L}$. Ao final do experimento, foram determinados os teores de potássio no lixiviado e no solo, até a profundidade de $0,8 \mathrm{~m}$. A lixiviação do potássio foi maior quando a fonte utilizada foi o $\mathrm{KCl}$. O termopotássio farelado mostrou maior enriquecimento dos teores de potássio na camada superficial do solo $(0-20 \mathrm{~cm})$, enquanto o $\mathrm{KCl}$ promoveu maior enriquecimento com potássio nas camadas subsuperficiais, sendo que esta fonte apresentou maior mobilidade no perfil, independentemente do tipo de solo. O termopotássio granulado disponibilizou menos potássio que o farelado fino, na camada superficial, e, nas demais camadas, não houve diferença significativa.

PALAVRAS-CHAVE: Adubação; percolação; lisímetros.

et al. 2009), capacidade de troca catiônica (CTC), regime hídrico da dose e solubilidade do fertilizante (Rosolem et al. 2006).

A CTC representa a quantidade de cátions que um solo é capaz de reter por unidade de peso ou volume (Raij 2011). A energia de retenção dos cátions trocáveis $\mathrm{Ca}^{2+}, \mathrm{Mg}^{2+}$ e $\mathrm{K}^{+}$, nos coloides do solo, segue uma série liotrópica, que leva em consideração a carga e o tamanho do íon hidratado, e o potássio é o quinto elemento desta série (Yamada \&

1. Trabalho recebido em dez./2012 e aceito para publicação em maio/2013 ( $\mathrm{n}^{\circ}$ registro: PAT 21438).

2. Universidade Federal de Uberlândia (UFU), Instituto de Ciências Agrárias, Departamento de Solos, Uberlândia, MG, Brasil. E-mails: ielenahas@yahoo.com.br, hseron@uol.com.br,ghk@uber.com.br. 
Roberts 2005). Como o potássio apresenta apenas uma carga de valência $\left(\mathrm{K}^{+}\right)$, é pouco adsorvido nos coloides do solo (Ernani et al. 2007). Portanto, em solos bem drenados e com menor CTC, a lixiviação é maior (Raij 2011).

Outro fator que influencia nas perdas de potássio por lixiviação é a fonte de potássio a ser utilizada (Yamada \& Roberts 2005). Sais de potássio de alta solubilidade conferem à solução do solo altos teores de potássio e, com isto, este elemento fica propício a ser lixiviado. Isto ocorre, principalmente, em solos arenosos, em razão da baixa CTC (Raij 2011).

O cloreto de potássio $(\mathrm{KCl})$, principal fonte de potássio utilizada na agricultura brasileira, é um sal altamente solúvel em água ( $58 \%$ de solubilidade), podendo ser facilmente lixiviado (Resende et al. 2006). Porém, com o avanço na tecnologia de produção de fertilizantes, buscam-se processos para controlar a taxa de liberação dos nutrientes, promovendo menores perdas e melhor adaptação às condições tropicais (Martins et al. 2010).

O termopotássio, fonte de potássio derivada do verdete, surge como fonte alternativa, para utilização na agricultura. O verdete é uma rocha silicática, que contém $7-14 \%$ de $\mathrm{K}_{2} \mathrm{O}$. Esta rocha é encontrada na região do Cedro de Abaeté do Estado de Minas Gerais e é composta, principalmente, por glauconita, feldspato potássico e micas (biotita e muscovita) (Piza et al. 2011).

Os minerais potássicos presentes no verdete apresentam baixa solubilidade (Silva et al. 2012). Para forçar a desagregação destes minerais e promover a liberação do potássio, os mesmos passam por um tratamento térmico (Orioli Júnior \& Coutinho 2009). No caso do verdete, a rocha é triturada e misturada com o carbonato de cálcio e, posteriormente, calcinada a $1.100^{\circ} \mathrm{C}$, originando um produto totalmente novo no mercado, que foi denominado termopotássio.

Com o intuito de entender o comportamento do termopotássio no solo, objetivou-se avaliar as perdas por lixiviação de potássio proveniente do cloreto de potássio granulado e do termopotássio (farelado fino e granulado), aplicados a amostras de dois tipos de solo.

\section{MATERIAL E MÉTODOS}

O experimento foi instalado na casa-de-vegetação do Instituto de Ciências Agrárias da Universi- dade Federal de Uberlândia, em 2010, utilizando-se delineamento inteiramente casualizado (DIC), com três repetições, em esquema fatorial. Foram utilizadas quatro fontes (testemunha, $\mathrm{KCl}$ granulado, termopotássio granulado e termopotássio farelado fino) e dois tipos de solo (Neossolo Quartzarênico órtico típico e Latossolo Vermelho distrófico). Os solos foram classificados segundo Embrapa (2006).

A caracterização química do cloreto de potássio $(\mathrm{KCl})$ granulado $(0,8-4,0 \mathrm{~mm})$, do termopotássio farelado fino $(0,5-3,34 \mathrm{~mm})$ e do termopotássio granulado (4-6 $\mathrm{mm}$ ) encontra-se na Tabela 1 .

Os dois tipos de solo utilizados no estudo foram extraídos dos primeiros $0,2 \mathrm{~m}$ superficiais da camada arável e consistiram de Latossolo Vermelho distrófico (LVd), cuja vegetação presente no local era uma pastagem degradada, e Neossolo Quartzarênico órtico típico (RQo), sob mata nativa. Estes solos foram caracterizados química e fisicamente (Embrapa 1999) e o silício no solo foi avaliado segundo Korndörfer et al. (2004) (Tabela 2).

A parcela experimental foi composta por uma coluna de lixiviação (lisímetro) de $0,8 \mathrm{~m}$ de altura e $0,2 \mathrm{~m}$ de diâmetro, dividida em oito anéis de $0,1 \mathrm{~m}$ de altura, que foram acoplados e fixados com o auxílio de uma fita adesiva. Esta fita foi passada em cada junção do anel, por quatro vezes, para evitar o escorrimento de água pelas paredes lisas da coluna. $\mathrm{Na}$ parte inferior de cada coluna, foi adaptada uma tela de aço e uma manta acrílica, para evitar a perda de solo, e um funil de aço galvanizado. A solução lixiviada era coletada em garrafa de plástico politereftalato de etila (PET), presente sob a coluna de lixiviação (lisímetro).

Os lisímetros foram preenchidos com as amostras de solo previamente secas ao ar e passadas em peneira com malha de 2,0 mm de diâmetro. As fontes de potássio foram aplicadas à dose de $3.000 \mathrm{~kg} \mathrm{ha}^{-1}$ de $\mathrm{K}_{2} \mathrm{O}$, na parte superior da coluna de lixiviação, e

Tabela 1. Caracterização química das fontes de potássio utilizadas no experimento (Uberlândia, MG, 2010).

\begin{tabular}{|c|c|c|c|c|}
\hline \multirow[t]{2}{*}{ Fonte } & $\begin{array}{c}\mathrm{K}_{2} \mathrm{O} \\
\text { total }^{(1)}\end{array}$ & $\begin{array}{c}\mathrm{Si} \\
\text { total }^{(2)}\end{array}$ & $\begin{array}{c}\mathrm{CaO} \\
\text { total }^{(3)}\end{array}$ & $\begin{array}{l}\mathrm{MgO} \\
\text { total }^{(3)}\end{array}$ \\
\hline & \multicolumn{4}{|c|}{$\mathrm{g} \mathrm{kg}^{-1}$} \\
\hline $\mathrm{KCl}$ granulado & 600,0 & - & - & - \\
\hline Termopotássio granulado & 65,0 & 113,3 & 325,1 & 70,0 \\
\hline Termopotássio farelado fino & 68,0 & 110,1 & 311,0 & 69,0 \\
\hline
\end{tabular}

Determinado segundo metodologia descrita por: ${ }^{(1)}$ EPA (1996); ${ }^{(2)}$ Korndörfer et al. (2004); ${ }^{(3)}$ Embrapa (1999) 
Tabela 2. Caracterização química e física da camada 0-20 cm do Latossolo Vermelho distrófico (LVd) e do Neossolo Quartzarênico órtico (RQo) (Uberlândia, MG, 2010).

\begin{tabular}{|c|c|c|c|c|c|c|c|c|c|c|c|c|c|}
\hline \multirow{2}{*}{ Solo } & \multirow{2}{*}{$\mathrm{pH}$} & $\mathrm{P}$ & $\mathrm{Si}$ & $\mathrm{K}$ & $\mathrm{Ca}$ & $\mathrm{Mg}$ & $\mathrm{H}+\mathrm{Al}$ & CTC & $\mathrm{V}$ & M.O. & Areia & Silte & Argila \\
\hline & & \multicolumn{2}{|c|}{$\mathrm{mg} \mathrm{dm}{ }^{-3}$} & & 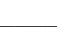 & $\mathrm{cmol}$ & -3 & 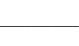 & \multicolumn{2}{|c|}{$\%$} & \multicolumn{3}{|c|}{$\mathrm{g} \mathrm{kg}^{-1}$} \\
\hline LVd & 5,3 & 0,7 & 6,0 & 0,07 & 0,1 & 0,0 & 3,3 & 3,47 & 5,0 & 0,2 & 546 & 54 & 400 \\
\hline RQo & 4,6 & 2,4 & 3,1 & 0,04 & 0,1 & 0,0 & 2,7 & 2,84 & 5,0 & 0,1 & 854 & 1 & 145 \\
\hline
\end{tabular}

pH $\left(\mathrm{H}_{2} \mathrm{O}\right) ; \mathrm{P} \mathrm{e} \mathrm{K}=\left(\mathrm{HCl} 0,05 \mathrm{~N}+\mathrm{H}_{2} \mathrm{SO}_{4} 0,0125 \mathrm{~N}\right) ; \mathrm{Ca}$ e $\mathrm{Mg}=(\mathrm{KCl} 1 \mathrm{~N}) ; \mathrm{H}+\mathrm{Al}=$ acidez potencial (acetato de cálcio); $\mathrm{V}=$ saturação por bases; $\mathrm{M} . \mathrm{O} .=$ método calorimétrico. A análise física utilizou o método da pipeta (Embrapa 1999) e o $\mathrm{Si}=\left(\mathrm{CaCl}_{2} 0,01 \mathrm{~mol} \mathrm{~L}^{-1}\right)$ a metodologia descrita por Korndörfer et al. (2004).

incorporadas ao primeiro anel da coluna, a $5,0 \mathrm{~cm}$ de profundidade, em todos os tratamentos. A quantidade de fertilizante adicionada a cada lisímetro foi calculada com base nos teores totais de $\mathrm{K}_{2} \mathrm{O}$ das fontes de potássio (Tabela 1).

A dose de $3.000 \mathrm{~kg} \mathrm{ha}^{-1}$ de $\mathrm{K}_{2} \mathrm{O}$ foi escolhida por refletir as práticas de campo, como, por exemplo, a adubação no fundo do sulco de plantio da cana-de-açúcar, onde se concentra o adubo, em até 15 vezes. A cana é plantada no espaçamento de $1,5 \mathrm{~m}$ entre as linhas e o potássio é aplicado de forma localizada, em uma faixa de, no máximo, 0,1 $\mathrm{m}$ de largura e 0,4 m de profundidade, no fundo do sulco de plantio. Este tipo de adubação corresponde a uma concentração, aproximadamente, 15 vezes maior, em relação a uma aplicação a lanço. Assim, uma dose de $200 \mathrm{~kg} \mathrm{ha}^{-1} \mathrm{de}$ $\mathrm{K}_{2} \mathrm{O}$, no fundo do sulco, corresponde a, aproximadamente, $3.000 \mathrm{~kg} \mathrm{ha}^{-1}$ de $\mathrm{K}_{2} \mathrm{O}$ aplicado em área total.

As amostras de solo, depois de acondicionadas nas colunas, foram umedecidas até atingirem a capacidade de campo, para propiciar a posterior percolação da água no solo, por meio da irrigação. Diariamente, foram adicionados, a cada coluna, cuja área era de $0,0314 \mathrm{~m}^{2}, 600 \mathrm{~mL}$ de água, com o auxílio de um regador. $\mathrm{O}$ excedente de cada parcela (lixiviado além da coluna) era coletado em uma garrafa PET e, a cada dois dias, transferido para um galão de $50 \mathrm{~L}$. Em cada parcela, havia um galão, e nele era armazenada a solução do solo que percolou das colunas. Durante 18 dias, os lisímetros foram irrigados com 10,8 L de água, no total, o que equivale a uma chuva de $344 \mathrm{~mm}$. Esta quantidade de água representa o somatório das chuvas que ocorrem na região Centro-Oeste do Brasil, no mês de janeiro.

Após 18 dias, o experimento foi finalizado e procedeu-se à determinação do potássio presente no lixiviado e em cada anel da coluna. A quantidade de potássio $\left(\mathrm{K}^{+}\right)$lixiviada foi calculada multiplicando-se o volume de líquido lixiviado e o teor de potássio da solução do solo, em leitura direta no fotôme- tro de chama. Os lisímetros foram desmontados, separando-se as amostras de solo de cada anel, e os dois primeiros anéis foram misturados, para simular a profundidade de amostragem de 0,0-0,2 m. Cada amostra de solo foi seca ao ar, passada em peneiras com malha de 2,0 mm de diâmetro e, posteriormente, foi determinado o potássio extraível do solo, com a resina trocadora de íons (Raij et al. 2001).

Os dados coletados foram submetidos à análise de variância, utilizando-se o programa estatístico Sisvar (Ferreira 2008). Quando o Teste F foi significativo ( $\mathrm{p}<0,05)$, as médias foram comparadas pelo Teste Tukey, a $5 \%$.

\section{RESULTADOS E DISCUSSÃO}

Não houve interação entre as fontes de potássio e os tipos de solo $(\mathrm{p}<0,05)$. O potássio lixiviado, proveniente do $\mathrm{KCl}$, foi maior do que o proveniente do termopotássio farelado e granulado. Além disto, não houve diferença entre o potássio lixiviado do tratamento testemunha e os tratamentos com termopotássio farelado e granulado (Tabela 3 ).

A percentagem de potássio total aplicado ao solo, recolhido na coluna de lixiviação proveniente do termopotássio farelado, foi de apenas $0,3 \%$, enquanto a do $\mathrm{KCl}$ foi de $26 \%$. Portanto, a perda de potássio por lixiviação abaixo da profundidade de $0,8 \mathrm{~m}$, proveniente do $\mathrm{KCl}$, foi 87 vezes maior do que quando comparada com o termopotássio (Tabela 3). Esta lixiviação do potássio oriundo do cloreto de potássio deveu-se à alta dose de $\mathrm{K}_{2} \mathrm{O}$ aplicada ao solo e à solubilidade em água (Raij et al. 2011).

Esses dados estão de acordo com Gabos et al. (2006), os quais observaram que o fornecimento de potássio, via termofosfato magnesiano potássico fundido, reduziu, significativamente, as perdas deste elemento por lixiviação, quando comparadas com o $\mathrm{KCl}$, independentemente do tipo de solo ou das doses utilizadas. 
Tabela 3. Quantidade de potássio coletada no lixiviado em Neossolo Quartzarênico órtico típico (RQo) e Latossolo Vermelho distrófico (LVd), para as fontes de potássio aplicadas superficialmente (Uberlândia, MG, 2010).

\begin{tabular}{|c|c|c|c|c|c|}
\hline \multirow{4}{*}{ Solo } & \multicolumn{4}{|c|}{ Fontes de potássio } & \multirow{3}{*}{ Média } \\
\hline & \multirow{2}{*}{$\mathrm{KCl}$} & \multicolumn{2}{|c|}{ Termopotássio } & \multirow{2}{*}{ Testemunha } & \\
\hline & & Farelado & Granulado & & \\
\hline & \multicolumn{5}{|c|}{ K lixiviado $\left(\mathrm{g}\right.$ coluna $\left.{ }^{-1}\right)$} \\
\hline RQo & $2,31(26)^{(1)}$ & $0,28(0,3)$ & $0,26(0,0)$ & 0,26 & $0,78 \mathrm{a}$ \\
\hline LVd & $2,09(26)$ & $0,08(0,3)$ & $0,07(0,1)$ & 0,06 & $0,58 \mathrm{~b}$ \\
\hline Média & $2,20 \mathrm{~A}^{(2)}$ & $0,18 \mathrm{~B}$ & $0,17 \mathrm{~B}$ & $0,16 \mathrm{~B}$ & \\
\hline
\end{tabular}

${ }^{(1)}$ Valores entre parênteses representam a percentagem de $\mathrm{K}$ lixiviado proveniente da fonte de $\mathrm{K}$ que foi aplicada, calculada segundo a equação: \%K perdido por lixiviação = [(K lixiviado da fonte $(\mathrm{g})$ - K lixiviado da testemunha $(\mathrm{g})) / \mathrm{K}$ total aplicado na adubação $(\mathrm{g})]$ x 100; ${ }^{(2)}$ Médias seguidas por letras distintas diferem entre si, pelo teste Tukey, a 5\%; CV(\%): 3,80; DMS solo: 0,02; DMS fonte: 0,04 .

$\mathrm{O} \mathrm{KCl}$ é uma fonte muito solúvel no solo, já que é constituído por minerais de silvita $(\mathrm{KCl})$ e silvinita $(\mathrm{KCl}+\mathrm{NaCl})$, que são de fácil solubilização (Nascimento et al. 2008). A rocha utilizada na produção do termopotássio é rica em minerais como o feldspato potássico e muscovita, de baixa cinética de dissolução, e biotita, que apresenta cinética de dissolução moderada (Martins et al. 2010).

Processos térmicos de fusão ou hidrotermais sobre esses minerais aumentam a solubilidade dos produtos, pela transformação mineralógica e formação de novas fases mais solúveis (Martins et al. 2010). Assim, a liberação do potássio do termopotássio para a solução do solo é gradual e, com isto, o potássio oriundo desta fonte fica menos sujeito a perdas por lixiviação.

Neste trabalho, também foi verificado que o nível de potássio presente no lixiviado das amostras de Neossolo foi maior que nas amostras de Latossolo (Tabela 3). Segundo Mielniczuk (1982), para uma mesma quantidade de potássio total, haverá menos potássio $\left(\mathrm{K}^{+}\right)$na solução, em solos com alta capacidade de troca catiônica (solos argilosos), o que refletirá em menores perdas de potássio por lixiviação, já que este nutriente se movimenta, com facilidade, verticalmente. Diferentemente, Werle et al. (2008) verificaram maiores perdas de potássio em solo argiloso, em relação ao solo de textura média, pois, neste caso, o solo argiloso apresentava, inicialmente, teor de potássio três vezes maior que o solo de textura média.

Especialmente em solos arenosos, com doses de $\mathrm{K}_{2} \mathrm{O}$ acima de 60-80 $\mathrm{kg} \mathrm{ha}^{-1}$, recomenda-se o parcelamento da adubação potássica, visando, principalmente, a reduzir as perdas de $\mathrm{K}^{+}$por lixiviação (Raij et al. 1997). Considerando-se os menores riscos deste tipo de perda, ao utilizar o termopotássio, pode- -se inferir que o parcelamento da adubação potássica, para as culturas, poderia ser dispensado, quando se utiliza esta fonte.

$\mathrm{O}$ potássio oriundo do $\mathrm{KCl}$ movimentou-se verticalmente, atingindo todas as camadas do lisímetro, indicando maior percolação deste elemento no perfil da coluna (Figura 1), o que já era esperado, por se tratar de uma fonte solúvel em água.

O teor de potássio trocável, na camada $0-0,2 \mathrm{~m}$, onde se encontra a maior parte das raízes de culturas anuais, apresentou-se superior no tratamento que recebeu o termopotássio farelado. Nas camadas abaixo de $0,2 \mathrm{~m}$, a concentração de raízes das culturas anuais é menor, mas a concentração das raízes de outras culturas, como a cana-de-açúcar, é maior. Nestas camadas subsuperficias, o teor de potássio no tratamento com o $\mathrm{KCl}$ foi superior ao dos outros tratamentos (Figura 1). Isto evidencia a menor movimentação do termopotássio, em relação ao $\mathrm{KCl}$, ao longo dos lisímetros.

Essa menor percolação do potássio pelo lisímetro, no tratamento com o termopotássio, ocorreu devido à sua baixa solubilidade em água e à sua capacidade em aumentar o $\mathrm{pH}$ e a CTC do solo (Bessa Filho 2011). A mobilidade do potássio, assim como a de outros cátions, diminui com o aumento da densidade de cargas negativas nos coloides do solo (Ernani et al. 2007) e, consequentemente, diminui a lixiviação do potássio, por promover maior retenção deste nutriente nos coloides do solo. Este aumento no $\mathrm{pH}$ do solo ocorre porque o termopotássio é oriundo da mistura do verdete com o calcário.

Além disso, o maior teor de potássio, na camada $0-0,2 \mathrm{~m}$, em relação ao $\mathrm{KCl}$, ocorre porque o termopotássio apresenta, no solo, uma dinâmica semelhante à do carbonato de cálcio, assim como a do $\mathrm{KCl}$ se assemelha à do gesso agrícola. 
(a)

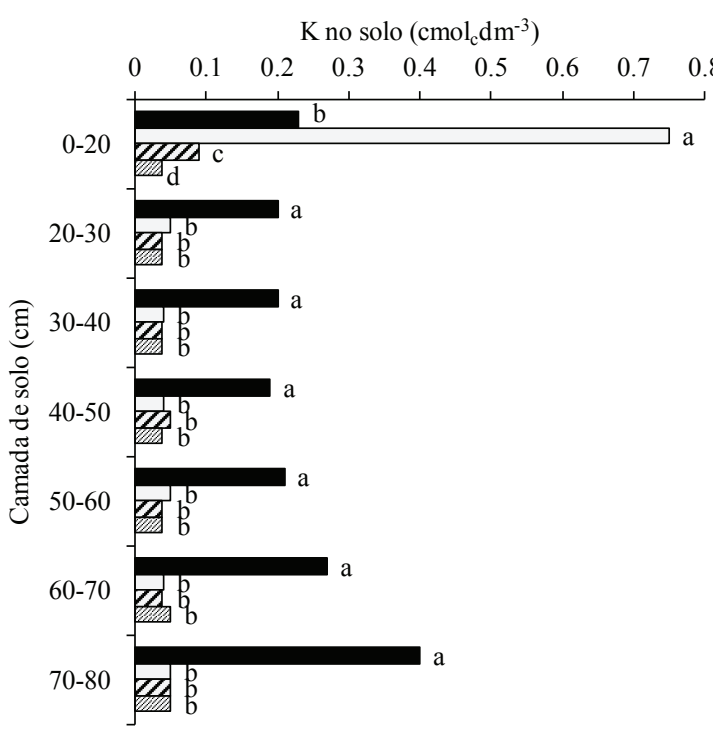

(b)

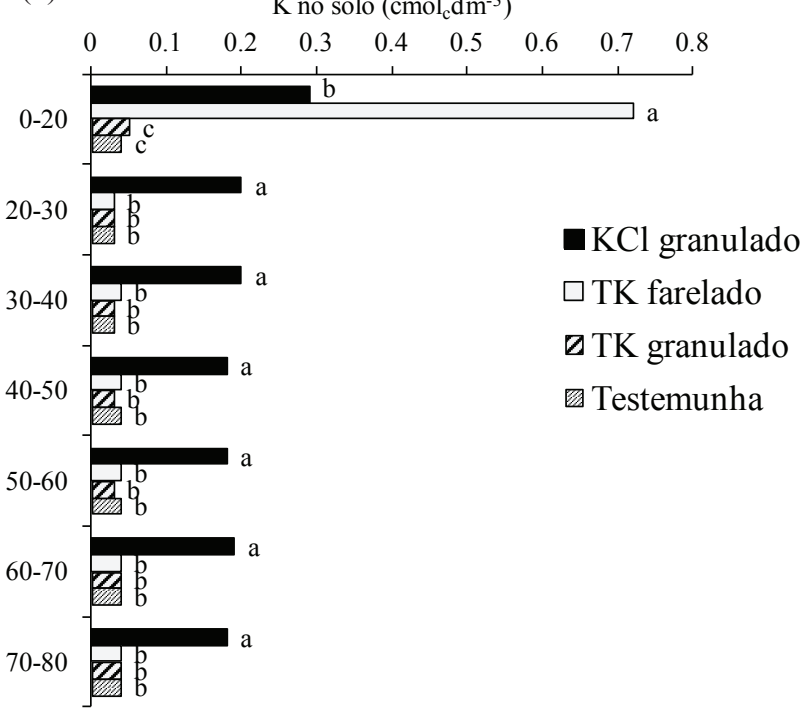

Figura 1. Teor de potássio (resina), nas camadas entre $0,0 \mathrm{~m}$ e 0,8 m, para o Latossolo Vermelho distrófico (LVd) (a) e o Neossolo Quartzarênico órtico típico (RQo) (b) submetidos à aplicação de diferentes fontes de potássio (Uberlândia, MG, 2010). Médias seguidas por letras distintas, dentro de cada camada, diferem entre si, pelo teste Tukey, a $5 \%$. $\mathrm{KCl}=\mathrm{cloreto}$ de potássio; $\mathrm{TK}=$ termopotássio.

O carbonato de cálcio, constituinte do calcário, apresenta baixíssima solubilidade e pouca movimentação no perfil do solo, quando o cálcio perde o par iônico (Raij 2011), como, possivelmente, ocorre com o potássio oriundo do termopotássio.

O gesso agrícola diminui os teores de alumínio trocável no solo, em profundidade (Carvalho et al. 2013). Isto é possível devido à formação do par iônico solúvel, sulfato de cálcio $\left(\mathrm{CaSO}_{4}^{\circ}\right)$, que é capaz de percolar, no perfil da coluna de lixiviação (Raij 1988). O cloreto de potássio tem o par iônico formado entre o potássio e o cloro e, por isto, como ocorre com o gesso, desce e tem efeito nas camadas subsuperficiais dos lisímetros.

O termopotássio farelado disponibilizou mais potássio na camada $0,0-0,2 \mathrm{~m}$ do que esta mesma fonte na forma granulada (Figura 1). Isto ocorreu porque a reatividade do termopotássio, na forma farelada, foi maior que na forma granulada. Segundo Raij (2011), com a redução no tamanho das partículas do fertilizante, a dissolução do K aumenta, desde que haja condições adequadas. Nas outras camadas, não houve diferença estatística entre as fontes de termopotássio.

\section{CONCLUSÕES}

1. A lixiviação do potássio foi maior quando a fonte utilizada foi o $\mathrm{KCl}$.
2. O termopotássio farelado mostrou maior enriquecimento dos teores de potássio na camada superficial do solo $(0-20 \mathrm{~cm})$, enquanto o $\mathrm{KCl}$ promoveu maior enriquecimento com potássio nas camadas subsuperficiais, com esta fonte apresentando maior mobilidade no perfil, independentemente do tipo de solo.

3. O termopotássio granulado disponibilizou menos potássio que o farelado fino, na camada superficial.

\section{AGRADECIMENTOS}

À Coordenação de Aperfeiçoamento de Pessoal de Nível Superior (Capes), Fundação de Amparo à Pesquisa do Estado de Minas Gerais (Fapemig), Conselho Nacional de Desenvolvimento Científico e Tecnológico (CNPq) e à empresa Verde Fertilizantes.

\section{REFERÊNCIAS}

BESSA FILHO, V. C. de. Fontes alternativas de potássio como corretivo de solo. In: CONGRESSO BRASILEIRO DE CIÊNCIAS DO SOLO, 33., 2011, Uberlândia. Anais... Uberlândia: SBCS, 2011. 1 CD-ROM.

CARVALHO, J. M. et al. Produtividade de cana soca sem queima em função do uso de gesso e vinhaça. Pesquisa Agropecuária Tropical, Goiânia, v. 43, n. 1, p. 1-9, 2013. 
EMPRESA BRASILEIRA DE PESQUISA AGROPECUÁRIA (Embrapa). Centro Nacional de Pesquisa de Solos. Manual de métodos de análise de solo. 2. ed. Rio de Janeiro: Embrapa Transferência de Tecnologia, 1999.

EMPRESA BRASILEIRA DE PESQUISA AGROPECUÁRIA (Embrapa). Centro Nacional de Pesquisa de Solos. Sistema brasileiro de classificação de solos. 2. ed. Rio de Janeiro: Embrapa Solos, 2006.

ENVIRONMENTAL PROTECTION AGENCY USA (EPA). Microwave assisted acid digestion of siliceous and organically based matrices (METHOD 3052). 1996. Disponível em: <http://www.epa.gov/wastes/hazard/ testmethods/sw846/pdfs/3052.pdf $>$. Acesso em: $20 \mathrm{fev}$. 2011.

ERNANI, P. R. et al. Mobilidade vertical de cátions influenciada pelo método de aplicação de cloreto de potássio em solos com carga variável. Revista Brasileira de Ciência do Solo, Viçosa, v. 31, n. 2, p. 393-402, 2007.

FERREIRA, D. F. Sisvar: um programa para análises e ensino de estatística. Revista Symposium, Lavras, v. 6, n. 1, p. 36-41, 2008.

GABOS, M. B. et al. Lixiviação de potássio aplicado ao solo na forma de cloreto de potássio e de termofosfato potássico fundido. In: FERTBIO, 2006, Bonito. Anais... Bonito: Embrapa, 2006. 1 CD-ROM.

KORNDÖRFER, G. H. et al. Análise de silício: solo, planta e fertilizante. Uberlândia: GPSi/ICIAG/UFU, 2004. (Boletim técnico, 2).

MARTINS, E. S. et al. Agrominerais: rochas silicáticas como fontes minerais alternativas de potássio para a agricultura. In: ADÃO, B. L.; LINS, F. (Eds.). Rochas e minerais industriais: usos e especificações. Rio de Janeiro: Cetem, 2010. p. 205-221.

MIELNICZUK, J. Avaliação da resposta das culturas ao potássio em ensaios de longa duração: experiências brasileiras. In: YAMADA, T. et al. (Eds.). Potássio na agricultura brasileira. Piracicaba: Instituto da Potassa e Fosfato, 1982.

NASCIMENTO, M. et al. Agrominerais: potássio. In: LUZ, A. et al. Rochas e minerais industriais. 2. ed. Rio de Janeiro: Cetem, 2008. p. 175-205.

NEVES, L. S.; ERNANI, P. R.; SIMONETE, M. A. Mobilidade de potássio em solos decorrente da adição de doses de cloreto de potássio. Revista Brasileira de Ciência do Solo, Viçosa, v. 33, n. 1, p. 25-32, 2009.

OLIVEIRA, M. V. A. M.; VILLAS BOAS, R. L. Uniformidade de distribuição do potássio e do nitrogênio em sistema de irrigação por gotejamento. Revista Engenharia Agrícola, Jaboticabal, v. 28, n. 1, p. 95-103, 2008.
ORIOLI JÚNIOR, V.; COUTINHO, E. L. M. Effectiveness of fused magnesium potassium phosphate for Marandú grass. Revista Brasileira de Ciência do Solo, Viçosa, v. 33, n. 6, p. 1855-1862, 2009.

PIZA, P. A. T. et al. Verdete da região do Cedro de Abaeté (MG) como fonte alternativa para potássio. Geociências, São Paulo, v. 30, n. 3, p. 345-356, 2011.

RAIJ, B. V. Fertilidade do solo e manejo dos nutrientes. Piracicaba: International Plant Nutrition Institute, 2011.

RAIJ, B. V. Gesso agrícola na melhoria do ambiente radicular no subsolo. São Paulo: Associação Nacional para Difusão de Adubos e Corretivos Agrícolas, 1988.

RAIJ, B. V. et al. Análise química para avaliação da fertilidade de solos tropicais. Campinas: Instituto Agronômico de Campinas, 2001.

RAIJ, B. V. et al. Recomendações de adubação e calagem para o Estado de São Paulo. 2. ed. Campinas: Instituto Agronômico de Campinas; Fundação IAC, 1997.

RESENDE, A. V. et al. O suprimento de potássio e pesquisa de uso de rochas "in natura" na agricultura brasileira. Espaço e Geografia, Brasília, DF, v. 9, n. 1, p. 19-42, 2006.

ROSOLEM, C. A. et al. Potássio no solo em consequência da adubação sobre a palha de milheto e chuva simulada. Pesquisa Agropecuária Brasileira, Brasília, DF, v. 41, n. 6, 2006.

SILVA, A. A. S. et al. Verdete de Cedro do Abaeté como fonte de potássio: caracterização, tratamento térmico e reação com CaO. Revista Matéria, Rio de Janeiro, v. 17, n. 3, p. 1062-1079, 2012.

WERLE, R. et al. Lixiviação de potássio em função da textura e da disponibilidade do nutriente no solo. Revista Brasileira de Ciências do Solo, Viçosa, v. 30, n. 5, p. 2297 2305, 2008.

YAMADA, T.; ROBERTS, T. L. Potássio na agricultura brasileira. Piracicaba: Associação Brasileira da Potassa e do Fosfato, 2005. 